\title{
Review on Ethical Issues in Ethnographic Study: Some Reflections ${ }^{1}$
}

\begin{abstract}
Nani Babu Ghimire
Abstract

Consideration of ethical issues in an ethnographic study is a significant matter to draw trustworthy findings and conclusions for the qualitative researchers. They need to be sensitive and honest on following the principles of ethical consideration while they are engaging in ethnographic research either in data collection or writing research papers. In this paper, I have employed literature review and self-reflective methodology to draw attention of the ethnographers to consider the ethical issues in doing ethnography. The findings and discussion have revealed that the ethnographic researchers should review the ethical aspects of their study from the Institutional Review Board; they must work in a natural setting to discover realistic experiences and/or struggles of the participants by respecting their cultural sensitivity and gaining permission and access to them as voluntary participants in the study. Moreover, the ethnographers need to take informed consent from their participants by securing confidentiality, maintaining anonymity, developing reciprocity, and preserving honesty for them in the research. Likewise, it is found that the ethnographic researcher must be conscious not to harm their participants during research work, and they should not fabricate their data, falsify the interpretation and plagiarize the already published materials in their research paper.
\end{abstract}

Keywords: Ethnography, ethical consideration, reflective experiences, natural setting, confidentiality

\section{Introduction}

The ethical issue is major concern in an ethnographic study since the researchers need to respect different perspectives of the participants regarding the nature of the field and participants of the study. Leavy (2017) has mentioned that ethics involve morality,

\footnotetext{
${ }^{1}$ Cite this article as: Ghimire, N. B. (2021). Contemporary Research: An Interdisciplinary Academic Journal, vol. 5 (1) DOI: https://doi.org/10.3126/craiaj.v5i1.40485

Nani Babu Ghimire, Lecturer, Siddhajyoti Education Campus, Sindhuli, PhD Scholar, School of Education, TU, Nepal; Email: nanibabughimire@gmil.com

Article history: Received on June 15; Accepted on September 10; Published on October 21

Peer reviewed under the authority of CRAIAJ, academic journal of Ghodaghodi Multiple Campus, Kailali, Nepal, with ISSN 2717-4611 (Print) and ISSN 2717-462X (Online).

(C) 2021 CRAIAJ
}

Full text of this article can be downloaded from www.craiaj.com and www.nepjol.info 
integrity, fairness, and truthfulness and they are of the utmost importance in social studies so that our research is not harmful (p. 24). Hammersley and Traianou (2012) have correspondingly used 'ethics' as 'morality' in social research which means that the researchers 'ought and ought not to do' in their research contexts. Agreeing with them Dahal (2020) has also revealed that research ethics is the researchers' moral behavior which is very much a private affair and directly linked to their personal outlook towards research participants. Moreover, Greenbank (2003) has maintained as "The moral values of researchers obviously have an important role to play in determining their research ethics" (p. 797) in an ethnographic study. Chilisa (2005) has further asserted ethical issues in qualitative research as "it includes codes of conduct that are concerned with the protection of the researched from physical, mental, and/ or psychological harm" (p.675). Likewise, Arifin (2018) has said, "The consideration of ethical issues is crucial throughout all stages of ethnographic study to keep the balance between the potential risks of research and the likely benefits of the research" (p. 30). Furthermore, Saldana (2015) has argued that ethics in research is very contextual because it is a "set of personal principles for interpersonal action and interpersonal conduct" (p. 80). Focusing on the principles of research ethics ethnographic researchers should protect "the human rights of research participants" (Byrne, 2001, p. 403) in their research work.

As value always impacts research, the researchers can uncover the truth by adopting "a value-neutral approach" (Greenbank, 2003, p.798) to reduce their anxieties in the ethnographic study by respecting the value of the research participants concerning qualitative research ethics. According to Johnson and Altheide (2002), research ethics can be categorized into "personal ethics, research ethics, intellectual ethics, professional ethics, and corporate (legal aspects) ethics" (p. 61). The ethnographic researchers need to follow these ethics during their research "to protect the privacy of the participants" (Creswell, 2009, p. 91), and to maintain the 'quality in research findings' and for 'academic integrity in their study because, in Dahal's (2020) words, "ethnographic study is value-laden and the research results vary as per the researcher's individual value system" (p. 12). In this regard, Rai (2020) has uttered that "ethnographic researches are guided by belief systems of understanding the world from the perspectives of research participants including their feeling of the pains and pleasure" (p. 46). To explore the perspectives of the participants in an ethnographic study, detailed and revealing ethnographic descriptions are required, and for that, ethics and quality are intrinsic elements in ethnographic work (Fetterman, 
2019) by giving emphasis on the researcher-participant relationship (Smith, 1999). As qualitative researchers are the primary instrument for data collection, they need to build virtuous rapport and trust with the participants. Rai (2020) has reported that "successful ethnographic research depends on the establishment of good rapport among the research participants" (p. 47) and, thus, the ethnographers ought to be open and transparent for gathering data without causing any harm to their research participants, preserving their dignity, and ensuring their privacy in the study (Creswell, 2012).

During my Doctor of Philosophy journey, I have been engaging in collecting, analyzing, and interpreting data by following the principles and ethical considerations of ethnographic research. In my study, I have been working with six teachers as participants of different three English medium instruction (EMI) community schools of Nepal to explore their language ideology, identity, and agency using critical ethnographic research design and multiple methods such as participant in-depth interviews, classroom observation, informal conversation, artifacts analysis, and memo writing. During my study, I have realized that ethical issues are the prominent concerns for the ethnographic researchers because I need to ensure that the participants have the autonomy to embroil in the study, defend their identity throughout the recruitment and dissemination process, and recommend clear and truthful research reporting without dishonesty to readers (Arifin, 2018). If ethnographic researchers do not pay close attention to maintaining ethical considerations in their study, the findings cannot have trustworthiness and transferability. With reference to this scenario, in this article, I want to inspect and explore the ethical issues of ethnographic study by reviewing literature and reflecting on my own experiences of critical ethnographic study.

\section{Methods and Procedures}

This is a literature review-based paper with critical reflection on my own experiences. First of all, I collected books, articles, and research papers from Google scholar and pro-quest database, and read them minutely focusing on the ethical consideration aspects of ethnographic study. I have critically reviewed them and have tried to link my experiences of the fieldwork in our socio-cultural context to the ethical practices found in the literature such as books, articles, and research papers. This paper has employed two methodological conceptions: literature review and researcher's reflection to explore the ethical issues of ethnographic study. The literature review provided me insight to draw the practice of ethical consideration in ethnographic study and reflection on my own 
experiences exposed me to critically analyze the ethical practices of the ethnographic study in the rural context of Nepal.

\section{Findings and Discussion}

The privacy of the participants in the ethnographic study is taken as a serious ethical issue. During the review of the literature, I found different ideas of ethical consideration which can be employed in ethnographic research to ensure the quality of the study and the privacy of the participants. Fetterman (2019) has discussed permission, honesty, trust, pseudonyms, reciprocity, guilty knowledge and dirty hands, and rigorous work as the ethical consideration of ethnographic study. Likewise, Creswell (2009) has maintained that being respectful of the research site, informed consent, and reciprocity, using ethical interview practices, maintaining confidentiality, assessment of risk, data access and ownership are the ethical issues of a qualitative study. Khanal and Phyak (2018) have mentioned that the qualitative researchers need to adopt informed consent, confidentiality, honesty and trust, reciprocity, neutrality (bracketing), no manipulation or falsification of data, and no violation of natural setting and maintaining integrity (professional integrity) as ethical consideration in the qualitative study. On the basis of the ideas revolved in the literature review, I have decided to develop the following themes to discuss the ethical issues of ethnographic study reflecting on my own study critically:

\section{Approval from Institutional Review Board}

The research plan of the researchers should be 'approved' (Gullion, 2016; Leavy, 2017) by the institutional review board (IRB) because Haines (2017) has asserted, "gaining ethical approval was an opportunity to discuss, gain feedback and improve the research (p. 233). Creswell (2009) has also emphasized on it and he has uttered, "Researchers need to have their research plans reviewed by the IRB on their college and university campuses" (p. 89). The review by IRB includes "seeking permission from the board, developing a description of the task, designing an informed consent form, and having the research proposal reviewed" (Creswell, 2012, p. 210). Further, Creswell (2012) has argued that "vulnerable populations represent high-risk populations and are carefully reviewed as participants by institutional review boards" (p. 231). In the context of Nepal, there is no such provision to review the research plan by the IRB in all subjects. My friends who are doing research in health education in my faculty have been reviewed their research plan from the IRB of their subject. Alternatively, my research plan has not been reviewed by any IRB because there is no such mechanism in my subject (English Education) under my faculty. The research committee of Graduate School of Education (GSE), Faculty of 
Education (FOE), Tribhuvan University (TU) conducted proposal viva and they allowed me to do the further work and I am doing my study now. As mentioned in the literature, my research plan is not reviewed by any review board. Instead, our research committee allowed me to do the research which itself plays the role of IRB in my subject. If this is not a valid process regarding ethical concern in an ethnographic study, as said by Leavy (2017) "IRBs are established in universities to ensure that ethical standards" (p. 32) of the study, it is essential to form an IRB for reviewing the research proposal of Ph. D. Candidate of English Education under TU in the coordination of GSE and FOE.

\section{Working in Natural Setting}

The ethnographic study is done in the natural environment with the collaboration between the researcher and the participants. As it studies people's behavior in 'natural setting', (Chesebro \& Borisoff, 2007; Frey, Botan, Friedman, \& Kreps, 1992), data collection of ethnographic research usually takes place in the territory of participants' everyday environment and their behaviors are not restricted and are also not controlled by the researchers (Hammersley \& Traianou, 2012). Similarly, Creswell (2009) has accentuated that "researchers need to respect research sites" (p. 90) while carrying out ethnographic research. As I found through accumulating the literature, I have been studying six teachers' behavior in three different community schools of the rural villages of Nepalese diverse society. I have been collecting the data in their own working place, i. e. school, by engaging with them in their everyday environment (inside and outside the classroom). I have been respecting each and every aspect of my research site without violating its naturalistic context, and I have included the natural context of school and the role of the participants through the thick description in my study. Engaging with my participants in informal conversation, developing rapport by visiting their houses, and developing collegial relationships without any hierarchy with them has enabled me to work in the natural setting in my study.

\section{Seeking Permission and Gaining Access}

The ethnographic researchers need to yield permission from the authority of the institutions and need greater access to the research site. Obtaining close access to the field in qualitative study creates a good relationship between the ethnographers and his setting. Riese (2018) has defined access in the context of qualitative research as "the process by which a researcher and the sites and/or individuals he or she studies relate to each other, through which the research in question is enabled” (p. 3). Creswell (2012) has suggested that the qualitative researchers need to "seek and obtain permissions from individuals and 
sites (p.205) to make successful access to the participants and research atmosphere". Likewise, Fetterman (2019) has opined that ethnographers must officially or informally seek permission to conduct their study either in government agencies or private institutions by submitting a formal request letter and receive written permission. However, I have visited the schools several times without taking written permission from the authority. Initially, as said by Byrne (2001) the purpose and procedures, as well as the risks and benefits, should be informed to the gatekeeper, I have informed the head teachers about my purpose of visiting schools is to collect data for my Pd. D. study. A gatekeeper is an individual (maybe a teacher, or a principal having "insider" status) who provides access to a site (Creswell, 2012), and facilitates the researchers to collect data by identifying participants and places in the research site. The head teachers allowed me to observe the classrooms and to take interviews with the teachers along with informal conversation and artifacts collection in the school premises.

In this sense, I do not need any written permission to make access to the site and, conduct the researches process in the field as mentioned by Fetterman. I have still not taken permission letters from the schools, though; I am conducting my study making good access to the teachers of the schools for a long time. But, as mentioned in the literature, I have given a letter for them to let me permission to collect data in their school for formality, and they are also agreed to give me a permission letter. Taking permission is an aspect of ethnographic study but it is not obligatory in our culture if we are familiar with the stakeholders of the research site. We can create access to the gatekeeper and the teachers (participants) through informal talk following our own culture as said by Riese (2018) that "qualitative researchers who are aware of the complexity of access will enable participants to take part in the research" (p. 110). The ability to gaining access to the participants and research site by the researchers shows that he/she can do the research on the issues.

\section{Voluntary Participation}

The participants should take part in the ethnographic research with their wish or will and/or they can involve themselves in the research in their own interest. According to Polonsky (2004), "Participation should be voluntary in all research, and there should be no coercion or deception. The researcher cannot force respondents to participate in his/her study. No one can hound them until they agree to participate" (p.58). Byrne (2001) has asserted that participants have the right to choose whether to participate in a study and the right to withdraw at any time (p. 401). 
In my study, I also make a list of possible participants who are teaching in EMI in primary classes of the community schools at first, and then, I choose two teachers (a male and a female) from each school. I consulted with them and informed my purpose assuring them that their participation ought to be voluntary and free from any pressure and should be based on informed consent. They agreed to work with me and I selected them as voluntary participation in research is understood as a choice or action performed without others' influence (Kilinc and Firat, 2017). I neither put any pressure on them nor trick them to take part in my study. They are happily engaging with me in participant classroom observation, interviewing, and informal conversation. They can withdraw their participation at any time when they want in my study.

\section{Respecting Cultural Sensitivity}

The role of the ethnographic researchers needs to be neutral and/or they cannot be biased towards any cultural and linguistic group in the society. Dahal (2020) has affirmed that cultural sensitivity is an inevitable ethical concern in an ethnographic study. Burnette, Sanders, Butcher, and Rand (2014) have stated that cultural sensitivity incorporates the historical context and cultural experiences, norms, values, beliefs, and behaviors of the population of ethical and culturally sensitive indigenous communities. Rai (2020) has suggested to the ethnographic researchers as "they should develop sound ethical relationships with the research participants and discuss or interact with them in a culturesensitive manner" (p. 46). Creswell (2012) has also advised respecting the indigenous culture during data collection. My research site is the dweller area of an ethical group such as Tamang, Sunuwar, Magar, Thami, Rai, Hayu, Newar, Majhi, and Madhesi who have their own identical culture and languages. I have paid much more attention to respect their cultural values, norms, and beliefs systems. I have become very careful to talk with them by following their cultural strategies such as politeness, respectfulness, simplicity, innocence, and shyness. I have never communicated with them about their internal hidden cultural matter that they want to keep secret since it is not the concern of study as well. I have engaged myself with them in their cultural festivals and other ethnic occasions as their family member by developing a close rapport with them. By increasing deep cultural relations with my participants, I have been working in the research field throughout the study.

\section{Taking Informed Consent}

Looking for the consent of the participants is usually a matter of ethical concern in an ethnographic study (Smith, 1999). Informed consent is an agreement between the 
researcher and the participants to conduct the research following the ethical issues of a qualitative study. The consent that is informed is voluntarily taken to secure personal privacy and guarantee the confidentiality of the participants, but we cannot always fulfill such guarantees because a written contract cannot be a substitute for trust (Eisner, 1991; Hammersley \& Traianou, 2012). But, Fetterman (2019) has remarked that written permission is particularly important for photographs if the ethnographers plan to use the pictures in a research report (p.143). The impressive style to take the informed consent is through writing information on institutional letterhead with adequate particulars to elicit ideas or data from the participants through interviews, participant observation, informal conversation, field notes, and memo writing (Hammersley \& Traianou, 2012; Polonsky, 2004).

The researcher can collect data with oral consent. Rai (2020) has opined, "It is not necessary to get the informed consent of participants as the informal conversation in regard to the research issue occurred covertly (p. 51). However, Creswell (2009) has stated, "The researcher develops an informed consent form for participants to sign before they engage in the research" (p. 89). The elements that can be included in the informed consent form in an academic ethnographic study are: identification of the researcher, brief introduction, purposes and procedures of the study, level, and type of participants, sponsoring institution (if any), a guarantee of confidentiality, description of benefits for participating, risks and discomforts to the participant, description of the assurance of anonymity, option to withdraw at any time, consent to an incomplete disclosure, provision of names of persons to contact if questions arise, and signature of participants and researcher (Byrne, 2001; Cresswell, 2007; Creswell, 2009; Leavy, 2017).

In my study, I collected preliminary data from participants with oral consent. As the participants are familiar with me, they are not hesitant to share their experiences and ideas with me even if we do not have written informed consent. But, for authenticity, I prepared a written informed consent form with essentials information and asked them to sign on it and I have also signed. They are agreed on the information of the consent form and they are providing appropriate time and effort for me to collect data. In the consent form, I have clearly mentioned that they have a right to withdraw from the study at any time if they cannot continue on the study because of their personal as well as professional cause.

Full text of this article can be downloaded from www.craiaj.com and www.nepjol.info 


\section{Securing Confidentiality}

Confidentiality is a form of secrecy that protects the privacy of the participants and it is of utmost importance in the ethnographic study (Baez, 2002; Creswell, 2012; Hammersley \& Traianou, 2012). Polonsky (2004) has mentioned that "confidentiality means that you know who the participants are, but that their identity will not be revealed in any way in the resulting report" (p. 62). The commitment to maintaining confidentiality also requires that data are not shared with academic colleagues, informally or via seminars, in a way that would allow the easy identification of the people and places to which the data relate (Hammersley \& Traianou, p.126). I am very sensitive on the confidentiality of my research participants. I only use the information and experiences that they share with me for my research purpose. I have been presenting the data obtained from them in the seminar with their permission by changing their personal and school names into pseudo names so that it does not harm them for their personal life. The audiences do not know who the participants are and where the data are collected from because of this secrecy technique.

\section{Maintaining Anonymity}

Anonymity is a technique used to preserve "the privacy of the people" (Gullion, 2016, p. 32) in an ethnographic study and it also serves to protect people from harm such as public discomfiture and physical menace. Anonymity is maintained by the qualitative researchers using pseudonyms, i.e., replacing actual names with invented ones, referring to people solely by the roles that they play such as teacher, student, doctor, nurse, patient, etc., using numbers or letters of the alphabet, for example, Participant 1, Participant 2; Teacher A, Teacher B, first names without second names, or just initials, changing facts or descriptors to protect participants or transcribing transcripts personally (Arifin, 2018; Byrne, 2001; Creswell, 2009; Hammersley \& Atkinson, 2007; Hammersley \& Traianou, 2012). As asserted by Gullion (2016) "Place names and locations can also be changed to protect privacy" (p. 33), I have given pseudonyms to the name of schools to bear the secrecy of the research site in my study. Moreover, I have transcribed data in my own study room using earphones to avoid the possibility of recordings being heard by other people. Likewise, I have mentioned pseudonym names to my participants in the verbatim quotes in the research report. All data of my study are stored in my personal laptop with a secret password and it is held only by me. As said by Creswell (2012) "participants may also wish to use their own name instead of a pseudonym" (p. 232), some of my participants have allowed me to use their real name in the research report, but I have not followed it because 
it is not an ethical matter and there may be a negative impact on those research participants in the future.

\section{Developing Reciprocity}

Involving individuals collaboratively and sometimes as co-researchers in the research may provide reciprocity (Creswell, 2009) in an ethnographic study. I have been working collaboratively with my participants while I am involving in classroom observation by teaching to the students, involving them in group work activities, and checking their classwork and homework. The reciprocal relationship between researcher and participant encourages the participants to dedicate their time, effort, experiences, and knowledge to notify and shape the researcher's study (Trainor \& Bouchard, 2013). My participants provide me time when I need and they have also thought that my study is also a concern of them because of my reciprocal relationship with them and/or they are closely attached with me. Fetterman (2019) has remarked that ethnographers consume a lot of people's time, and they owe something in return for reciprocity. For this, they may "offer time and expertise to them by teaching English or Math, milking cows and cleaning chicken coops, or helping to set up a new computer and learn to use the software" (147). He further argued that direct payment is not a highly recommended form of reciprocity (ibid). Creswell (2009) has claimed that "the risk of harm can also arise from a researcher's commitment to reciprocity - with repaying participants for any time and effort they have given in answering questions" (p. 90) which is also regarded as an unethical activity in an ethnographic study. I have also been teaching in the class, holding workshops to the teachers for developing teaching skills in EMI, and conducting discussion sessions for their difficulties. I have visited my participants' houses/accommodations and have tried to become a part of their household activities by carrying water from the tap and cutting vegetables. I requested them to take tea in the local cafeteria but I have not paid cash to them thinking it is an unethical matter of ethnographic study. I have also given fruits and other goods as gifts to my participants for rapport building because this is a part of our culture since we never go to any people's house with empty hands and it is not regarded as an unethical issue in our culture.

\section{Preserving Honesty and Trust}

Ethnographers must be honest and they usually maintain an implicit trust with the participant to complete their task (Fetterman, 2019). Furthermore, he has stressed, "people often accord ethnographers the same level of trust that they give to priests, rabbis, psychiatrists, clinical psychologists, doctors, and lawyers" (p. 146). In a study, Phyak 
(2016) has reported that he established a strong rapport and built trust with the participants not only being distant observers in the back of the classroom but also participated of reflexive dialogues with them, which helped him develop a deep trust with his participants. I have also developed a deep rapport with my participants as an honest ethnographic researcher and they have been communicating with me frankly and expressing their opinions openly by trusting me. I have shared my experiences and progress (including publication) that I have received during this study and I have also discussed it with them which has helped them to develop trust in me and they have been engaging during my study eagerly and confidently.

\section{Do not Harm}

Harm is inherent to all research and it can result from the actions of researchers (Baez, 2002; Hammersley \& Traianou, 2012). Leavy (2017) said that 'do no harm is the primary principle governing the protection of research participants' (p.32). According to Polonsky (2004), "There are a number of ways in which participants can be harmed: physical harm, psychological harm, emotional harm, social harm" (p.62). The ethnographers need to be conscious of not doing these harms to their participants. They must also consider the special needs of vulnerable populations such as prisoners, the mentally ill and the acutely ill, minors (under the age of 19), mentally incompetent participants, victims, pregnant women or fetuses, and individuals with AIDS to protect them from unintentional harm in their study (Arifin, 2018; Creswell, 2009; Polonsky, 2004; Raudonis, 1992). Ethics codes suggest that harm must be avoided and the researchers must evade serious harm to anyone in their ethnographic study (Hammersley \& Traianou, 2012). Fetterman (2019) has suggested, "The use of pseudonyms is a simple way to disguise the identity of individuals and protect them from potential harm (p.147). Additional, Polonsky (2004) has recommended that "the harm can be addressed by providing counseling services with the issue to the participants" (p. 63). It is essential to maintain 'cultural sensitivity and 'ethical concern of taking photographs' in research not to harm the participants (Rai, 2020). My study does not consist of vulnerable populations and I have not faced any problems that cause harm to my participant. However, I am conscious on the ethical concern of ethnographic research to protect my participant from any harmful activities.

\section{Avoiding Scientific Misconduct}

Scientific misconduct includes fabrication, falsification, and plagiarism in research work. These include errors in citing the primary literature, using the wrong statistics, elimination of data points to make the results appear significant, misleading titles, failure 
to report results properly, duplication of data, improper assignment of authorship, and repeated carelessness (Lawrence, 2019, p. 1). Moreover, Polonsky (2004) has described that there may be a temptation to “cut and paste" others' work to form new ideas, intentional misrepresentation of data, creating artificial data without field visits and writing inaccurate results and conclusions are manipulations of qualitative data. Further, Creswell (2009) has exemplified scientific misconduct as "the potential of suppressing, falsifying, or inventing findings to meet a researcher's or an audience's needs which are fraudulent practices and they are not accepted in professional research communities (p. 92). I have been doing practice to avoid plagiarism in writing seminar papers, literature reviews, preparing proposals and writing progress reports during my study. I have been collecting data by meeting my participants face-to-face in their proper workplace as I do not need to fabricate the data. Likewise, I am analyzing and interpreting the data following the principles of qualitative data analysis by making codes and categories and developing themes based on the collected data which hinders me from falsification of the data.

\section{Conclusion}

The research plan needs to be reviewed by Institutional Review Board (IRB), but in the case of English Education in GSE, FOE, TU, there is no IRB to review my research. I have been doing my study without any review by IRB. My experiences show that it is essential to create an IRB for reviewing the research plan of English Education in Nepal. Conducting the ethnographic study in a natural setting is vital without violating its real flavor in the field. Concerning this aspect, my study has also been included my role in the natural context of school with participants through the thick description. However, taking permission and gaining access to the research site is an aspect of ethnography, it is not an obligatory aspect in our culture if we are familiar with the participants and research site. The participants are involved in the ethnographic research in their own interest and they have the right to withdraw at any time by informing researchers. The researchers need to consider the cultural sensitivity of the participants to interact with them by developing ethical relationships and respecting their cultural heritage.

The researchers can secure their participants' privacy by ensuring anonymity or confidentiality in an informed consent form. Making an informed consent form and doing signature on it is not compulsory to guarantee the privacy of the participants since the researchers can do it with oral and/or informal consent, and I have also done my initial phase of study without it, later I have taken written consent from my participants for 
formality. Confidentiality and anonymity need to be maintained by the qualitative researchers by using pseudonyms to protect their participants from physical and social harm. I have also given pseudonyms to the schools and the participants in my study. Working together with the participants helps to enrich deep relations between the researchers and participants which is crucial for maintaining reciprocity. I have also been working together in the classroom with the teachers and the students by engaging in participant classroom observation. The ethnographers need to consider the special needs of vulnerable populations to save from any harm while they are taking data with them. The qualitative researchers must be honest in the eyes of the participants to maintain an implicit trust for completing their research work. Furthermore, there is no room for ethnographic researchers to do any fabrication of data, falsification of results, and plagiarizing in writing reports because these fraudulent practices are not accepted in academia.

\section{References}

Arifin, S. R. M. (2018). Ethical considerations in qualitative study. International journal of care scholars, 1(2), 30-33. Retrieved from https://journals.iium.edu.my/ijcs/index.php/ijcs/article/view/82

Baez, B. (2002). Confidentiality in qualitative research: reflections on secrets, power and agency. Qualitative research, 2 (1), 35-58, doi:10.1177/1468794102002001638

Burnette, C. E., Sanders, S., Butcher, H. K. and Rand, J. T. (2014). A toolkit for ethical and culturally sensitive research: An application with indigenous communities. Ethics and social welfare, 8 (4), 1-19, doi: 10.1080/17496535.2014.885987

Byrne, M. (2001).The Concept of informed consent in qualitative research. AORN journal, 74(3), 401-403, doi:10.1016/s0001-2092(06)61798-5

Chesebro, J. W., \& Borisoff, D. J. (2007). What makes qualitative research qualitative? Qualitative research reports in communication, 8 (1), 3-14, doi: 10.1080/17459430701617846

Chilisa, B. (2005). Educational research within postcolonial Africa: A critique of HIV/AIDS research in Botswana. International journal of qualitative studies in education, 18 (6), 659-684, doi: 10.1080/09518390500298170 
Creswell, J. W. (2007). Qualitative inquiry and research design: Choosing among five traditions: Thousand oaks: Sage.

Creswell, J. W. (2009). Research design: Qualitative, quantitative, and mixed methods approaches, Thousand Oaks, CA: Sage publications.

Creswell, J. W. (2012). Educational research: Planning, conducting, and evaluating quantitative and qualitative research, New York: Pearson.

Dahal, B. (2020). Research ethics: A perspective of South Asian context. Edukacja 1 (152), 9-20, doi: 10.24131/3724.200101

Eisner, Elliot (1991).The enlightened eye: Qualitative inquiry and the enhancement of educational practice, New York: Macmillan.

Fetterman, D. M. (2019). Ethnography: Step-by-step. Sage Publications.

Frey, L. R., Botan, C. H., \& Friedman, P. G., \& Kreps, G. (1992). Interpreting communication research: A case study approach. Englewood Cliffs, NJ: Prentice Hall.

Greenbank, P. (2003). The role of values in educational research: The case for reflexivity. British educational research journal, 29(6), 791-801, doi: 10.1080/0141192032000137303

Gullion, J. S. (2016). Writing ethnography. Brill Sense.

Haines, D. (2017). Ethical considerations in qualitative case study research recruiting participants with profound intellectual disabilities. Research ethics, 13 (3-4), 219232, doi: 10.1177/1747016117711971

Hammersley, M. \& Atkinson, P. (2007). Ethnography: Principles in practice ( $3^{\text {rd }}$ ed.). Routledge

Hammersley, M., \&Traianou, A. (2012).Ethics in qualitative research: Controversies and contexts, Sage. 
Johnson, J. and Altheide, D. L. (2002) 'Reflections on professional ethics', in Will C. van den Hoonaard (ed.) Walking the tightrope: Ethical issues for qualitative researchers (pp. 59-69). Toronto: University of Toronto Press

Khanal, P. \& Phyak, P. (2018). Class slide on ethical consideration for qualitative research. Kathamandu: Tribhuvan University.

Kilinc, H., \& Firat, M. (2017). Opinions of expert academicians on online data collection and voluntary participation in social sciences research. Educational sciences: Theory \& practice, 17 (5), doi:10.12738/estp.2017.5.0261

Lawrence, R. (2019). The importance of ethics in scientific research. Lipids, 54 (1), 5-7, doi: 10.1002/lipd.12118

Leavy, P. (2017). Research design: Quantitative, qualitative, mixed methods, arts-based, and community-based participatory research approaches. New York: The Guilford Press.

Polonsky, M. J. (2004). Ethical considerations.In The Foundations. 53-75. Retrieved from https://www.sagepub.com/sites/default/files/upmbinaries/4999_Polonski_Chapter_5.pdf

Phyak, P. (2016). For Our Cho: Tlung: Decolonizing Language Ideologies and (Re) Imagining Multilingual Education Policies and Practices Nepal (Doctoral dissertation, University of Hawaii, Manoa). Retrieved from: https://scholarspace.manoa.hawaii.edu/bitstream/10125/51616/2016-12-phdphyak.pdf

Rai, I. M. (2020). Emergent positioning in insider ethnographic field: Deconstructing the ideological frame of insider or outsider or both. Dhaulagiri journal of sociology and anthropology, 14, 46-52, doi: 10.3126/dsaj.v14i0.27280

Raudonis, B. M. (1992). Ethical considerations in qualitative research with hospice patients. Qualitative health research, 2(2), 238-249, doi: 10.1177/104973239200200207 
Riese, J. (2018). What is “access” in the context of qualitative research? Qualitative research, doi:10.1177/1468794118787713

Saldana, J. (2015). Thinking qualitatively: Methods of mind. London: Sage.

Smith, B. A. (1999). Ethical and methodologic benefits of using a reflexive journal in hermeneutic-phenomenologic research. Image: The journal of nursing scholarship, 31(4), 359-363, doi: 10.1111/j.1547-5069.1999.tb00520.x

Trainor, A., \& Bouchard, K. A. (2013). Exploring and developing reciprocity in research design. International journal of qualitative studies in education, 26(8), 9861003.doi: 10.1080/09518398.2012.724467

Full text of this article can be downloaded from www.craiaj.com and www.nepjol.info 